\title{
Other License Status
}

National Cancer Institute

\section{Source}

National Cancer Institute. Other License Status. NCI Thesaurus. Code C118472.

A disciplinary action has been taken against a license but its status is different from active, suspended, revoked, or resolved. 